\title{
Analysis and Application of the Mechanical Properties of the Karst Collapse Column Fillings
}

\author{
Zhibin Lin, ${ }^{1}$ Boyang Zhang $\mathbb{D},{ }^{1,2}$ Xiaofei Gong, ${ }^{3}$ Limin Sun, ${ }^{4}$ Wenzhen Wang, \\ Dafang Yang, ${ }^{1}$ Yanlin Yang, ${ }^{5}$ Ming Guo, ${ }^{6}$ and Xia-Hui Pan ${ }^{1}{ }^{1}$ \\ ${ }^{1}$ School of Civil Engineering, Henan Polytechnic University, Jiaozuo 454003, Henan, China \\ ${ }^{2}$ School of Energy Science and Engineering, Henan Polytechnic University, Jiaozuo 454003, Henan, China \\ ${ }^{3}$ Aerospace Information Research Institute, Chinese Academy of Sciences, Beijing 100094, China \\ ${ }^{4}$ School of Architectural Engineering, Zhengzhou Business University, Gongyi 451299, Henan, China \\ ${ }^{5}$ Academic Publishing Center, Henan Polytechnic University, Jiaozuo 454003, Henan, China \\ ${ }^{6}$ School of Emergency Management, Henan Polytechnic University, Jiaozuo 454003, Henan, China \\ Correspondence should be addressed to Xia-Hui Pan; panxh@hpu.edu.cn
}

Received 4 February 2021; Revised 17 March 2021; Accepted 23 March 2021; Published 5 April 2021

Academic Editor: Junfei Zhang

Copyright (c) 2021 Zhibin Lin et al. This is an open access article distributed under the Creative Commons Attribution License, which permits unrestricted use, distribution, and reproduction in any medium, provided the original work is properly cited.

The filling material of the karst collapse column (KCC) is easy to be activated by mining. During this process, the mechanical properties of KCC fillings change, and its water resisting capacity constantly deteriorates and thus often leads to water inrush disaster. In this study, the samples of KCC fillings were taken on-site and then were remolded by the consolidation drainage method. The variation laws of the compressive strength, tensile strength, cohesive stress, internal friction angle, and permeability of the filling samples with respect to the consolidation pressure and moisture content were tested and analyzed. Based on an engineering example, the yield and activation and particle loss of the filling material of the KCC are analyzed. A mechanism for the lagging water inrush of KCC in the process of mining is proposed. The main results of the present study can be concluded concisely as follows. (1) The KCC fillings show obvious soft rock characteristics in the process of uniaxial compression and Brazilian split. The ratio of the uniaxial compressive strength to splitting tensile strength is between $12: 1$ and $8: 1$. The larger the consolidation pressure or the smaller the moisture content, the larger the ratio. (2) With the increase of consolidation pressure or the decrease of moisture content, the uniaxial compressive strength, elastic modulus, splitting tensile strength, cohesive stress, and internal friction angle of the filling material of the KCC increase linearly, while its permeability increases exponentially. (3) When the crack field of the surrounding rocks of the stope is connected with the KCC, its filling material will continue to yield, activate, and migrate under the fluid-solid coupling effect and finally result in the lagging water inrush from the KCC.

\section{Introduction}

As a major coal-producing area, North China has an approved production capacity of 2.82 billion tons per year, accounting for nearly $66 \%$ of China's coal reserves $[1,2]$. At present, the shallow coal resources in North China are gradually exhausted, and coal mining is gradually extended to the deep underground $[3,4]$. The deep mining of coal leads to considerable increase of the confined mining area of Ordovician limestone aquifer, which aggravates the threat of Ordovician limestone karst water disaster $[5,6]$. As a special geological structure in North China, the karst collapse column (KCC) is a natural connecting channel between coal seam and Ordovician limestone karst water. Severe accidents of mine water inrush from KCCs have occurred several times in North China, resulting in a large number of casualties and economic losses $[7,8]$.

Researchers have conducted a lot of research on the seepage law and the water inrush mechanism of KCC. Based on the theories of elasticity, fluid mechanics, and nonlinear dynamics, the seepage characteristics of KCC were studied extensively, and several models were proposed, such as the 
side wall water inrush model [9], the seepage well model [10], the flow regime transition model [11], and the plug model [12]. On the basis of the aforementioned four theoretical models, many scholars have carried out a lot of numerical simulation work on the KCC [13-17]. Experimentally, Wang et al. [18] have developed a model test device of KCC and carried out the indoor model test. A large number of indoor seepage tests of fractured rocks in KCC were carried out [19-23]. The abovementioned research studies improved the early warning mechanism of KCC water inrush and played a significant guiding role in the field. In the recent two large-scale KCC water inrush accidents that occurred at Huaibei Taoyuan mine in 2013 and Huainan Panji No. 2 mine in 2017, only one worker was injured.

As mentioned above, researchers carried out a lot of research on the seepage characteristics and water inrush mechanism of KCC with fruitful results. Nevertheless, the KCC is mainly composed of fractured rock mass and interstitial material, i.e., the fillings. Previous experimental research mainly focused on the fractured rock mass, and the experimental work on the mechanical properties of the karst collapse column fillings (KCCF) is rare. However, the water inrush of KCC is mainly caused by unconsolidated or consolidated KCC connecting with Ordovician limestone water. Under the joint action of coal mining and highpressure Ordovician limestone water, the KCCF is constantly yielding and activated, resulting in considerable change of the internal void structure of the KCC, the gradual increase of the permeability, and the weakening of the water blocking capacity, which eventually leads to the water inrush accident of KCC. Study on the mechanical properties of the KCCF can help to reveal the mechanism of water inrush of $\mathrm{KCC}$ in essence. Because of the difficulty to take the KCCF sample completely in site, in this study, we use the dehydrated consolidation remodeling method to prepare the sample of KCCF, test, and analyze its uniaxial compressive strength, splitting tensile strength, triaxial compressive strength, and permeability. We then analyze the variation laws of the tensile and compressive strengths, the cohesive stress, the internal friction angle, and the permeability with consolidation pressure and water content. Taking a project as an example, the KCC is divided into three parts, i.e., the loose fractured rocks, the natural pores, and the fillings. The activation and subsequent loss of the filling material are modeled as the dynamical change of the porosity of fillings in the plastic yield zone. The lagging water inrush process of the KCC is simulated by FLAC ${ }^{3 \mathrm{D}}$ software.

\section{Sample Preparation and Test Methods}

2.1. Test Material. Shanxi Lu'an Group Sima Coal Industry Co., Ltd., No. 2 Mining Area 1211 working face wind tunnel exposed a KCC X3 (Figure 1(a)). Geophysical data show that the KCC X3 has developed to about $150 \mathrm{~m}$ above the No. 3 coal seam roof. The density of fillings in X3 is about $2000 \mathrm{~kg} /$ $\mathrm{m}^{3}$, and the vertical stress is about $3 \mathrm{MPa}$. In this study, the test filling material is taken from among the fractured rocks of KCC X3. Before our tests, they were crushed, dried, and then sieved by a $1 \mathrm{~mm}$ round-hole sifter (Figure $1(\mathrm{~b})$ ).

2.2. Sample Preparation. The modified triplex high-pressure consolidometer and a self-developed sample mold (Figure 2) were used to prepare the filling sample of KCC X3. The specific preparation steps are as follows:

(1) According to the density of the filling material onsite, weigh a certain weight of the filling material particles of the KCC and add a certain proportion of water (fixed moisture content), mix them evenly, and pour them into the test mold.

(2) Put the sample and the mold altogether into the triplex high-pressure consolidometer and then start to load step by step. Meanwhile, record the displacement of the sample every 2 hours using the dial gauge. When the displacement increment is less than $0.008 \mathrm{~mm} / \mathrm{h}$, the next level load is applied.

(3) After loading to the prescribed value, remove the mold and dry the sample

According to the actual occurrence state of KCCFs, we have considered various moisture contents and different consolidation pressures in the process of sample preparation (Figure 3).

(1) Moisture content $\omega$. The exposed section of KCC X3 has a local water pouring phenomenon, and the moisture content of the filling material is high [24]. When preparing the samples, the moisture content can be chosen as $15 \%, 18 \%, 20 \%, 22 \%$, and $25 \%$, respectively, while keeping the maximum consolidation pressure constant at $3 \mathrm{MPa}$.

(2) Consolidation pressure $p$. The actual vertical pressure at the sampling site of the KCC is about $3 \mathrm{MPa}$. However, considering the influence of the transverse tectonic stress, the maximum consolidation pressure of the sample is set as $1 \mathrm{MPa}, 2 \mathrm{MPa}, 3 \mathrm{MPa}, 4 \mathrm{MPa}$, $5 \mathrm{MPa}$, and $6 \mathrm{MPa}$, respectively, under the condition of constant moisture content at $20 \%$. They correspond to the $7-12$ th loading level.

In order to ensure the same height of samples, we reserve enough height before consolidation and then cut off the surplus height of samples after consolidation, so as to ensure the same height of samples under different consolidation pressures.

2.3. Test Methods. The strength of the samples is tested using multifunctional machines, i.e., MTS816.02 for uniaxial compression (Figure 4(a)) and DNS100 for Brazilian splitting (Figure 4(b)). The MTS815.02 electrohydraulic servo rock testing machine is used to conduct the triaxial compression and permeability tests (Figure 4(c)). The permeability tests adopt the transient seepage method. The relationship between the seepage velocity $V$ and the transient pressure gradient $\xi$ is $[25,26]$ 


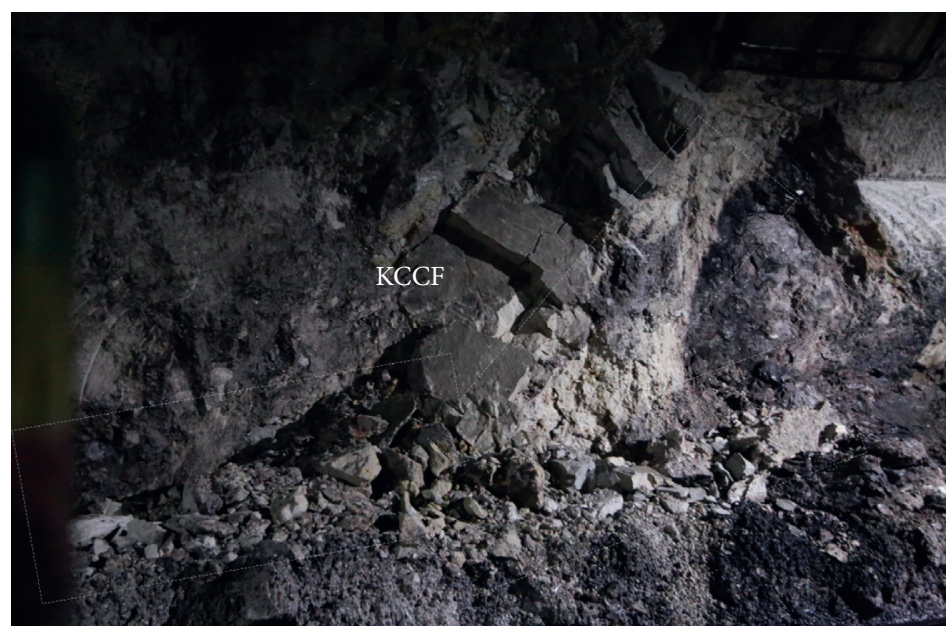

(a)

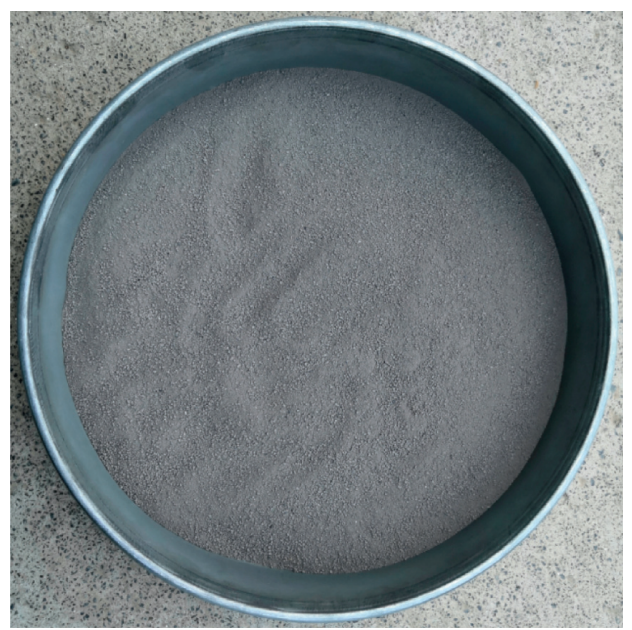

(b)

FIGURE 1: Test filling material of KCC X3. (a) KCC X3 at Sima coal mine. (b) Crushed and dried filling material particles.

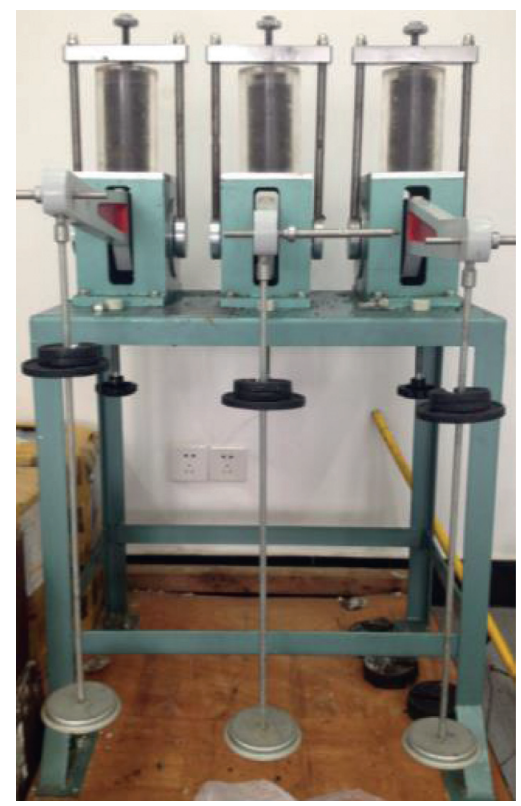

(a)

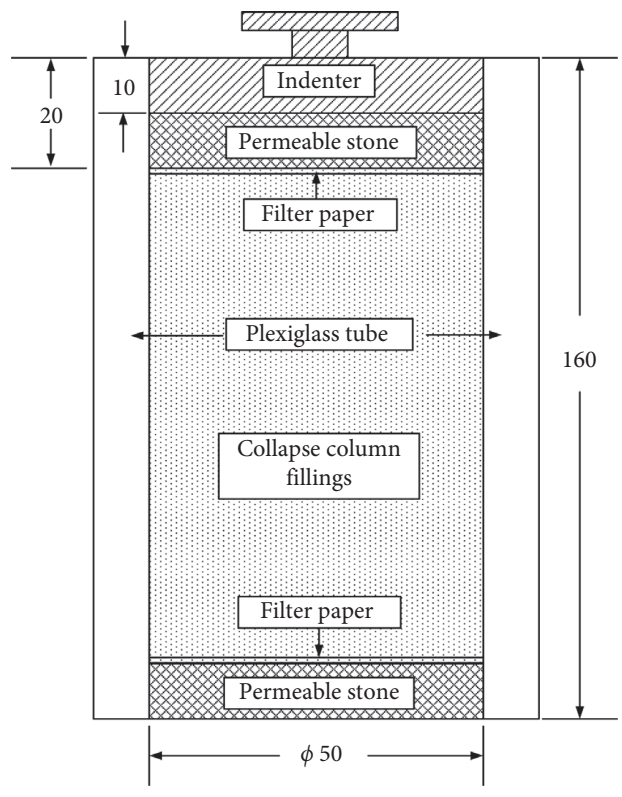

(b)

FIGURE 2: Instruments for sample preparation. (a) The modified triplex high-pressure consolidometer. (b) Schematic of the self-developed sample mold.

$$
V=\frac{c_{f} B H}{2 A} \frac{d \xi}{d t},
$$

where $c_{f}=0.556 \times 10^{-9} \mathrm{~Pa}^{-1}$ is the compressibility of water, $B=0.332 \times 10^{-6} \mathrm{~m}^{3}$ is the volume of water tank of the testing machine, $H=0.05 \mathrm{~m}$ is the height of sample, $t$ denotes the time, and the transient pressure gradient $\xi=\left(p_{2}-p_{1}\right) / H$, where $p_{2}$ and $p_{1}$ are the instantaneous water pressures at the upper and lower ends of the sample, respectively. The axial load is $1 \mathrm{kN}$. The confining pressure is $3 \mathrm{MPa}$.
Assuming the seepage obeys Darcy's law, the permeability $k$ can be expressed as

$$
k=\frac{c_{f} B H \mu}{2 t_{f} A} \ln \frac{\xi_{0}}{\xi},
$$

where $\mu=1.01 \times 10^{-3} \mathrm{~Pa} \cdot \mathrm{s}$ is the dynamic viscosity coefficient of water under room temperature, $t_{f}$ is the acquisition time, and $\xi_{0}=20 \mathrm{MPa} / \mathrm{m}$ is the initial pressure gradient in the test. 


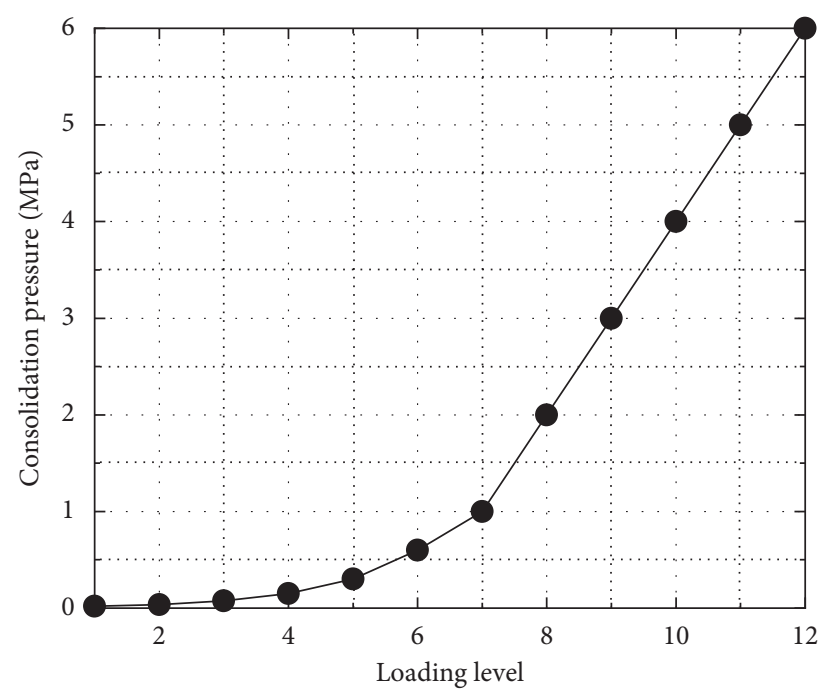

Figure 3: Consolidation pressure versus different loading levels.

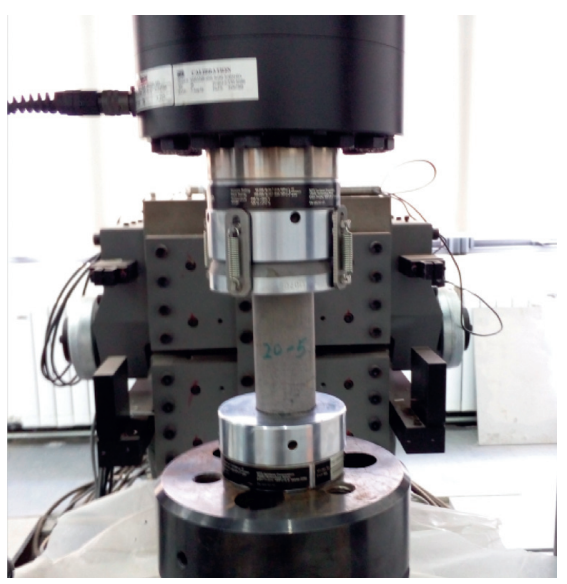

(a)

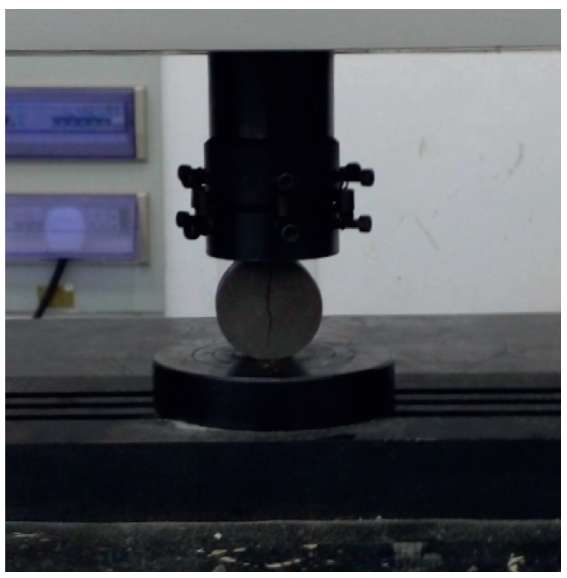

(b)

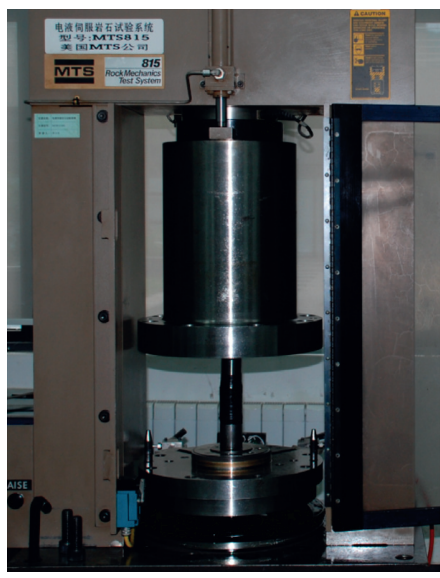

(c)

FIgURE 4: Testing machines. (a) Uniaxial compression. (b) Brazilian split. (c) Triaxial compression and permeability.

\section{Test Results Analysis}

3.1. Uniaxial Compressive Strength and Elastic Modulus. The stress-strain curves of the uniaxial compression tests for the filling samples of KCC are shown in Figure 5. Similar to rock, a typical curve can be divided into the following four stages (taking the sample $\omega=15 \%$ in Figure $5(\mathrm{~b})$, for example):

(1) The compaction stage OA. In this stage, the stress increases rapidly with the increase of strain, and the relationship between stress and strain is linear.

(2) The elastic stage AB. In this stage, the stress increases approximately linear with the strain, but the slope is smaller than that in the compaction stage.

(3) The yielding stage BC. In this stage, the material of the KCCF samples begin to damage and the damage is continually accumulated. The stress rate gradually slows down with the increase of strain, and finally, the stress reaches the peak point $C$.
(4) The softening stage CD. After reaching to the peak point, the stress decreases rapidly with the increase of strain, but there is no cliff-like decrease, showing good ductility.

Typical failure modes for uniaxial compression of the KCCF samples under different consolidation pressures and moisture contents are shown in Figure 6. When the consolidation pressure is less than $3 \mathrm{MPa}$ or the moisture content is larger than $20 \%$, the adhesive stress between the filling material particles is relatively weak. Thus, in this case, the failure mode of the uniaxial compression sample is fracture induced by transverse extension due to Poisson's effect (Figure 6(a)). When the consolidation pressure increases or the moisture content decreases, the failure of the KCCF samples is still dominated by transverse tension, but some oblique shear cracks begin to appear (Figure 6(b)). When the consolidation pressure exceeds $5 \mathrm{MPa}$ or the moisture content is lower than $15 \%$ because of the strong cohesion between the filling material particles, the uniaxial 


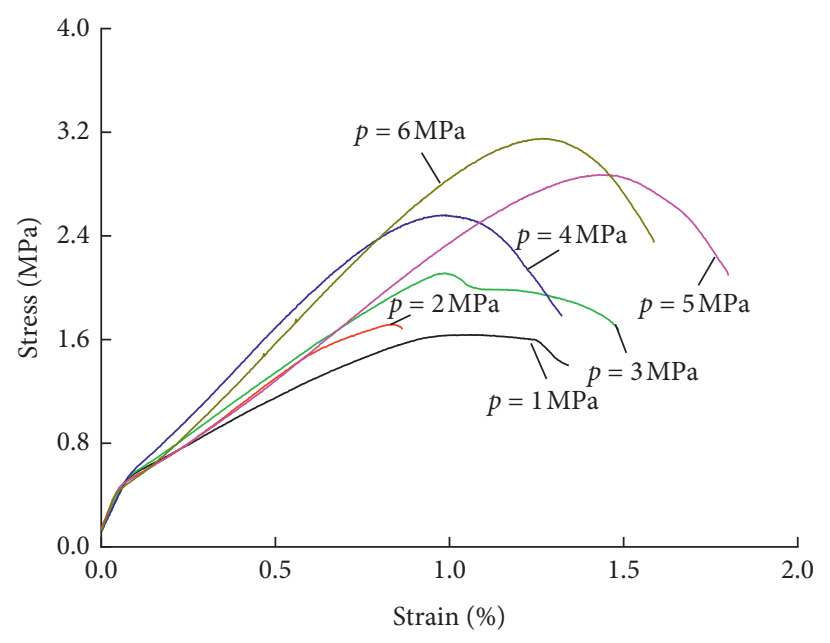

(a)

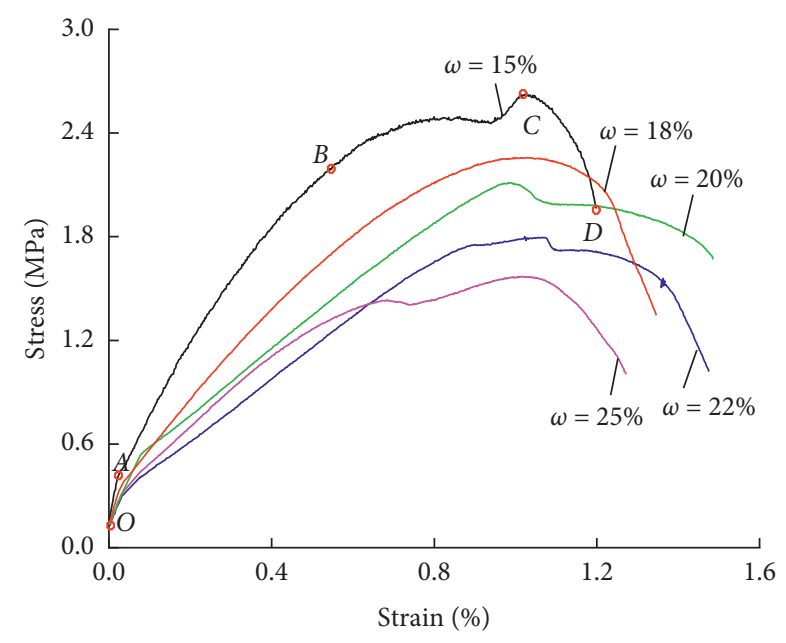

(b)

Figure 5: The stress-strain curves of uniaxial compression for different KCCF samples. (a) Different consolidation pressures $(\omega=20 \%)$. (b) Different moisture contents $(p=3 \mathrm{MPa})$.

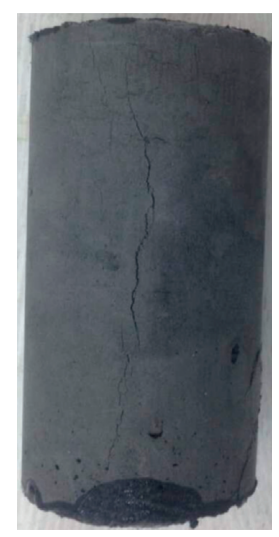

(a)

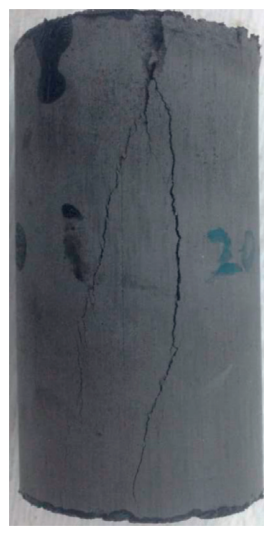

(b)

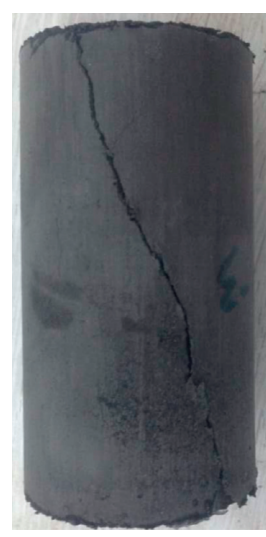

(c)

Figure 6: Typical failure modes of the uniaxial compression samples of KCCFs. (a) Tensile failure. (b) Combined tensile-shear failure. (c) Shear failure.

compression failure of the sample is mainly oblique shear failure (Figure 6(c)).

The tested uniaxial compressive strength $\sigma_{c}$ of the KCCF samples under different consolidation pressures and moisture contents are shown in Figure 7, from which we can see that

(1) The uniaxial compressive strength increases approximately linear with the increase of the consolidation pressure (Figure 7(a)). The uniaxial compressive strength increases by about $0.33 \mathrm{MPa}$ for every $1 \mathrm{MPa}$ increment of the consolidation pressure. This is caused by two reasons: on the one hand, under the action of high consolidation pressure, the internal structure of the filling material of KCC is more compact; on the other hand, the consolidation time of high consolidation pressure is greater than that of low consolidation pressure, and the consolidation degree of the sample will also be improved by long-term consolidation.

(2) The uniaxial compressive strength decreases with the increase of the moisture content, which also shows an approximate linear relationship (Figure 7(b)). The uniaxial compressive strength decreases about $0.11 \mathrm{MPa}$ when the moisture content increases by $1 \%$. This is because the higher the moisture content of the sample, the greater the porosity and the worse the homogeneity. Therefore, the uniaxial compressive strength of the sample with high moisture content must be less than that of the sample with low moisture content.

The results of the tested elastic modulus of the filling material of KCC are shown in Figure 8. Due to the random distribution of the pore structures in the filling material, the elastic moduli of KCCF samples fluctuate with different 


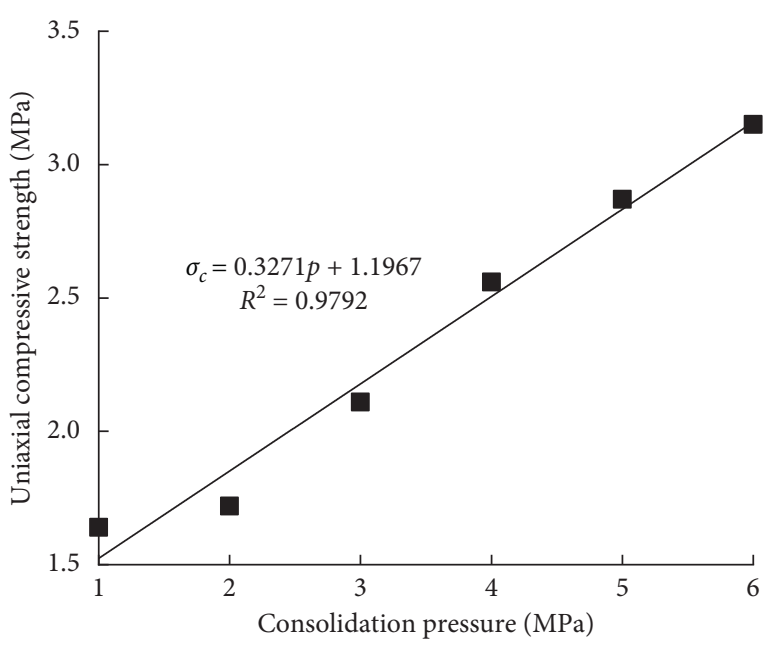

Test results

Curve fitting

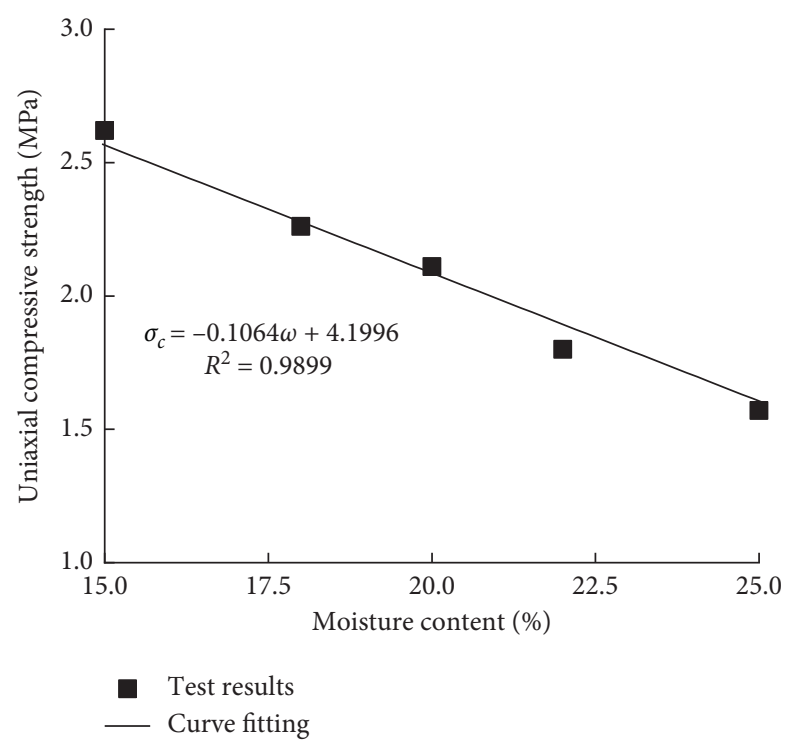

(b)

Figure 7: Uniaxial compressive strength of KCCFs. (a) Different consolidation pressures $(\omega=20 \%)$. (b) Different moisture contents $(p=3 \mathrm{MPa})$.

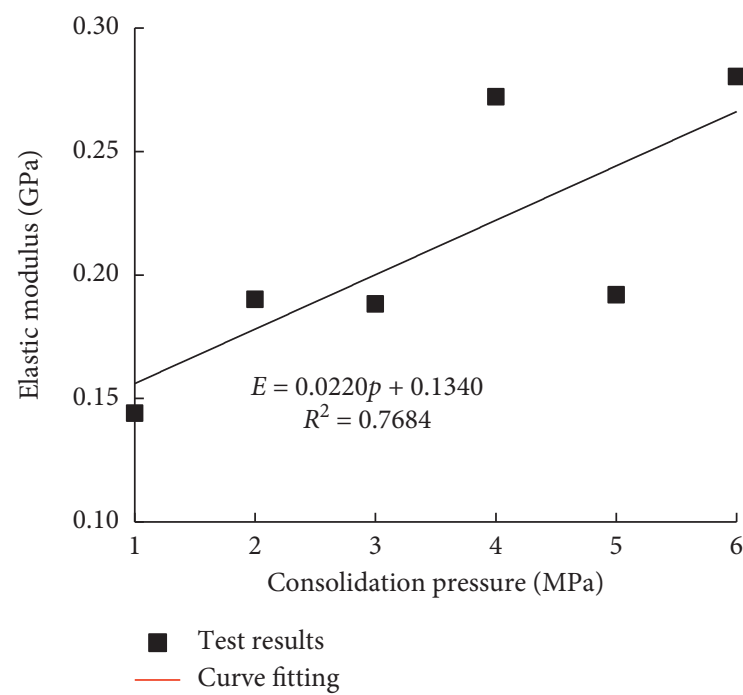

(a)

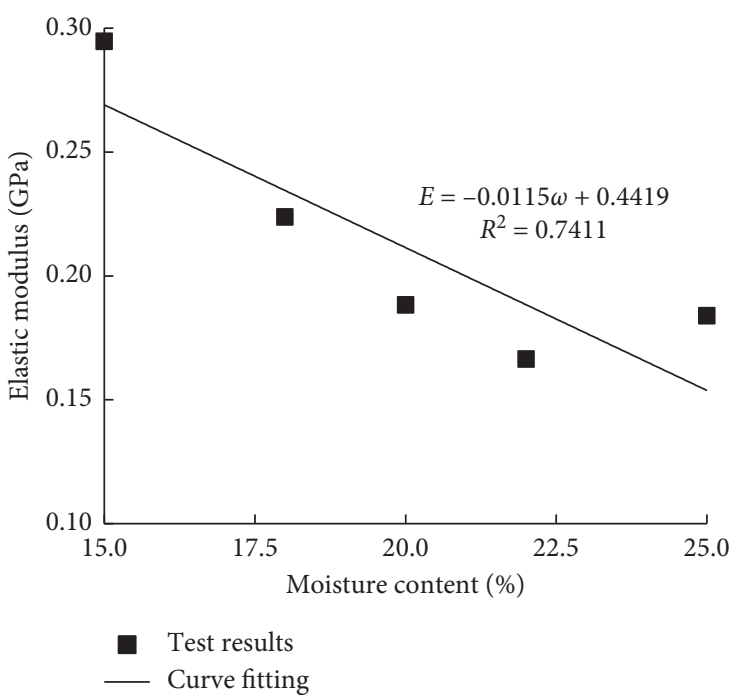

(b)

FIGURE 8: Elastic modulus of KCCFs. (a) Different consolidation pressures ( $\omega=20 \%)$. (b) Different moisture contents $(p=3 \mathrm{MPa})$.

consolidation pressures and moisture contents. However, their values are between $0.15 \mathrm{GPa}$ and $0.30 \mathrm{GPa}$, and they increase roughly with the increase of the consolidation pressure and the decrease of the moisture content.

3.2. Splitting Tensile Strength. The load-displacement curves of the KCCF samples in Brazilian split tests are shown in Figure 9. All the curves have gone through the compaction stage, the linearly elastic stage, the yielding stage, and the drop stage. Among them, the postpeak drop stage curve presents a certain nonlinear drop characteristics, which is obviously different from brittle rocks (such as red sandstone), but similar to sandy mudstone [26, 27]. In addition, the uniaxial compression stress-strain curve of KCCF samples (Figure 5) is also similar to that of the soft rock. Therefore, it can be concluded that both the tensile and compressive properties of the KCCF materials are close to those of the soft rock.

Figure 10 shows the variation of the splitting tensile strength $\sigma_{t}$ of the KCCF samples with respect to the consolidation pressure and the moisture content. We can see that with the increase of consolidation pressure and the 


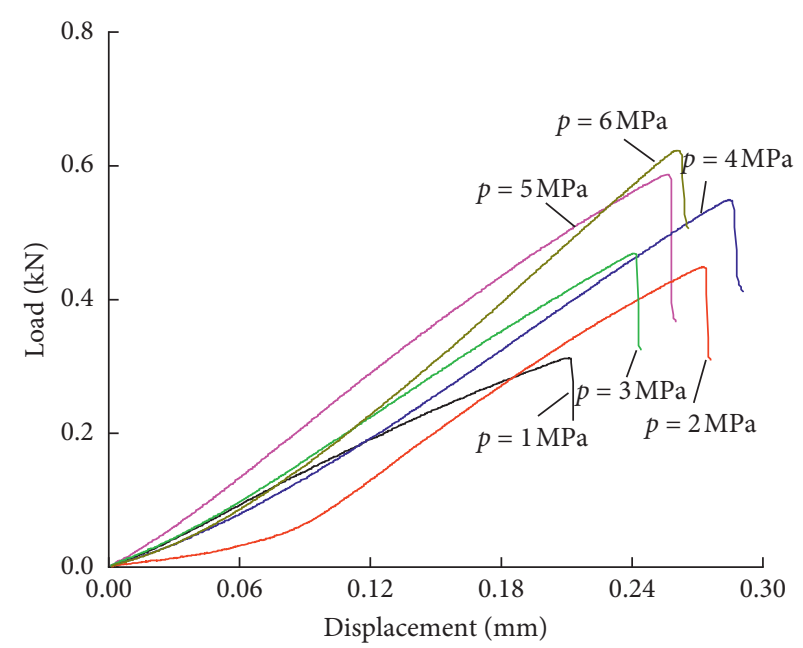

(a)

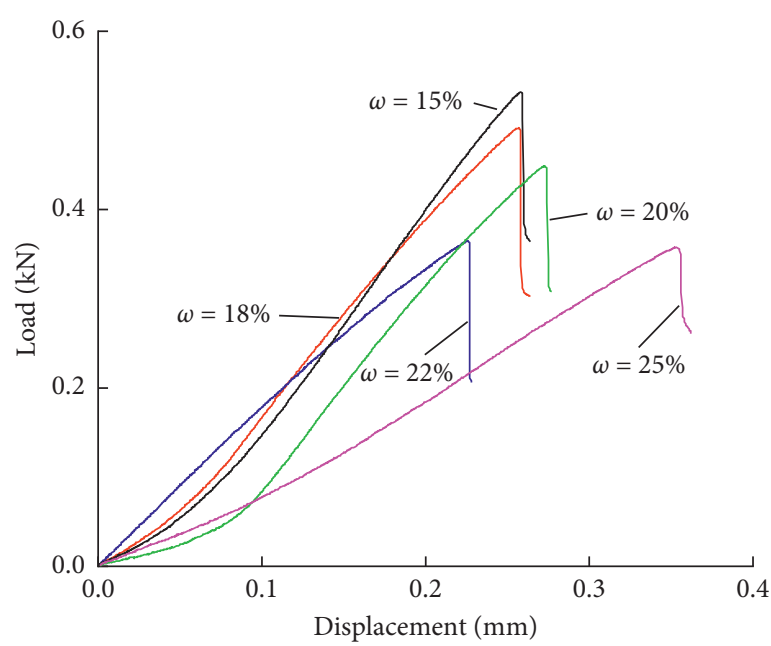

(b)

FIgure 9: Load-displacement curves of KCCFs in Brazilian split tests. (a) Different consolidation pressures $(\omega=20 \%)$. (b) Different moisture contents $(p=3 \mathrm{MPa})$.

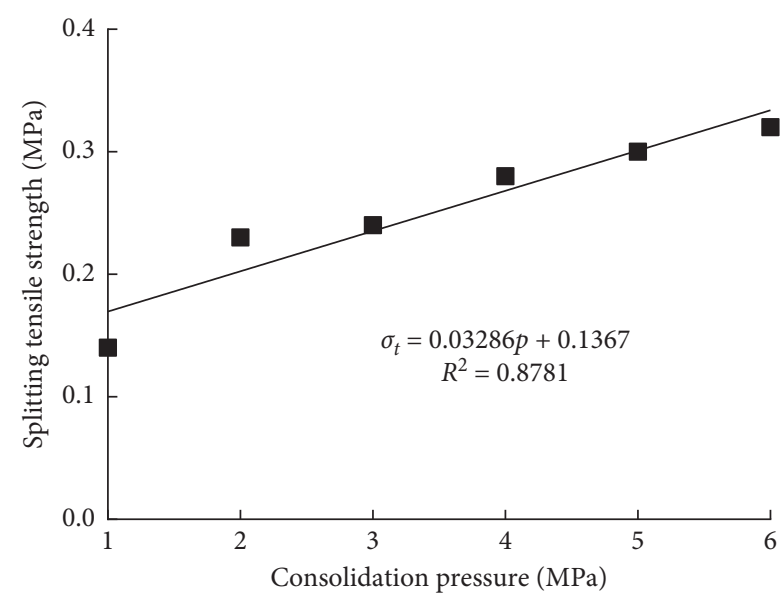

- Test results

- Curve fitting

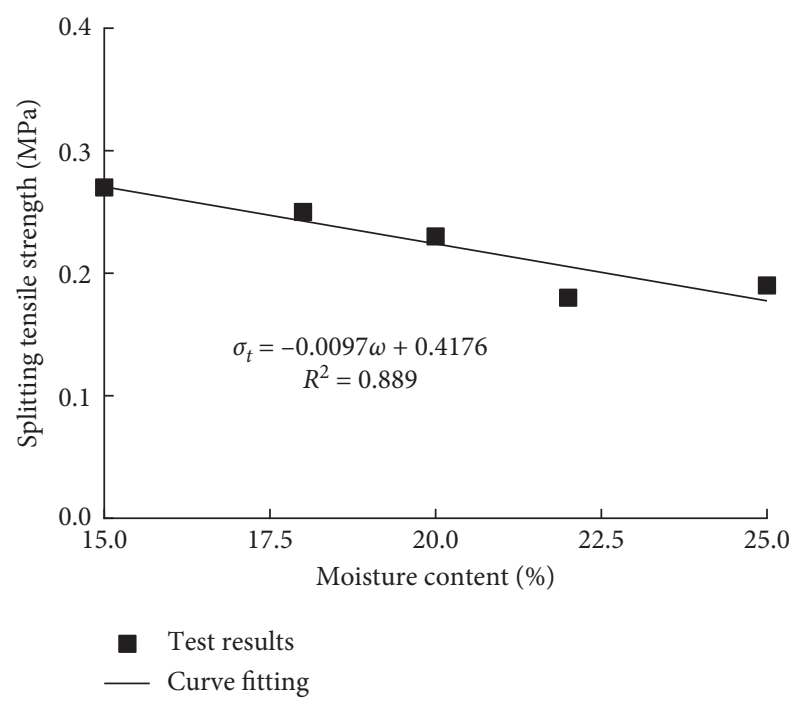

(b)

(a)

FIGURE 10: Splitting tensile strength of KCCFs. (a) Different consolidation pressures ( $\omega=20 \%)$. (b) Different moisture contents ( $p=3$ MPa).

decrease of moisture content, the splitting tensile strength increases linearly. The tensile strength increases from $0.14 \mathrm{MPa}$ to $0.32 \mathrm{MPa}$ when the consolidation pressure increases from $1 \mathrm{MPa}$ to $6 \mathrm{MPa}$. When the moisture content increases from $15 \%$ to $25 \%$, the tensile strength decreases from 0.27 MPa to 0.19 MPa. Compared with Figure 8, it can be seen that in the same condition, the tensile strength of the KCCF samples are about 1/12-1/8 of their corresponding compressive strength. The greater the consolidation pressure or the smaller the moisture content, the greater the ratio of the tensile strength to compressive strength of the sample.

3.3. Cohesive Stress and Internal Friction Angle. The triaxial compressive stress-strain curves of KCCF samples under different consolidation pressures and moisture contents are shown in Figure 11. It is seen that the maximum principalstress-difference of the KCCF samples will increase with the increase of the axial strain, and the increasing rate will gradually slow down. Under the same axial strain condition, the greater the consolidation pressure or the lower the moisture content, the greater the maximum principal-stressdifference. However, when the axial strain reaches a certain value, the maximum principal-stress-differences of all the KCCF samples will nearly unchanged, and the drop phenomenon after the peak is not obvious. This indicates that the KCCFs show similar plastic yield characteristics with soil under certain confining pressure, and its cohesion and internal friction angle remain nearly unchanged with respect to plastic strain. 


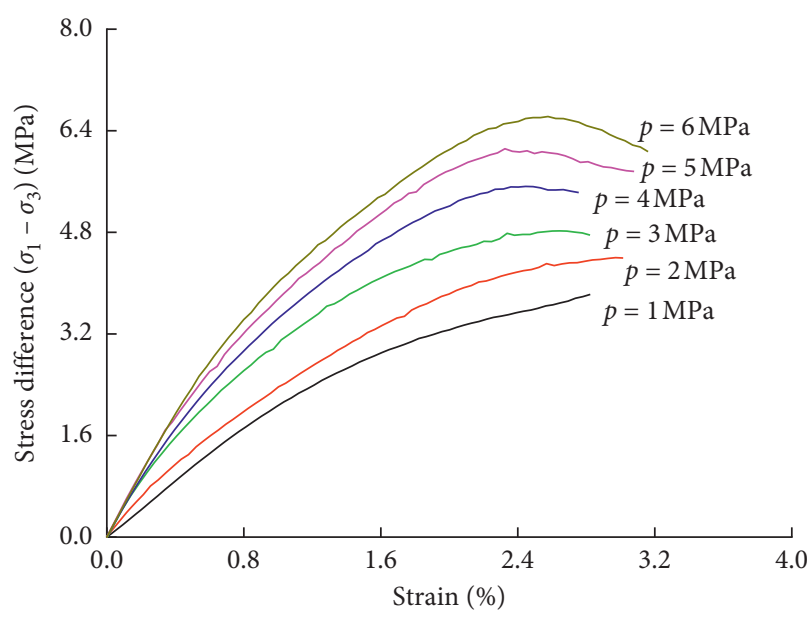

(a)

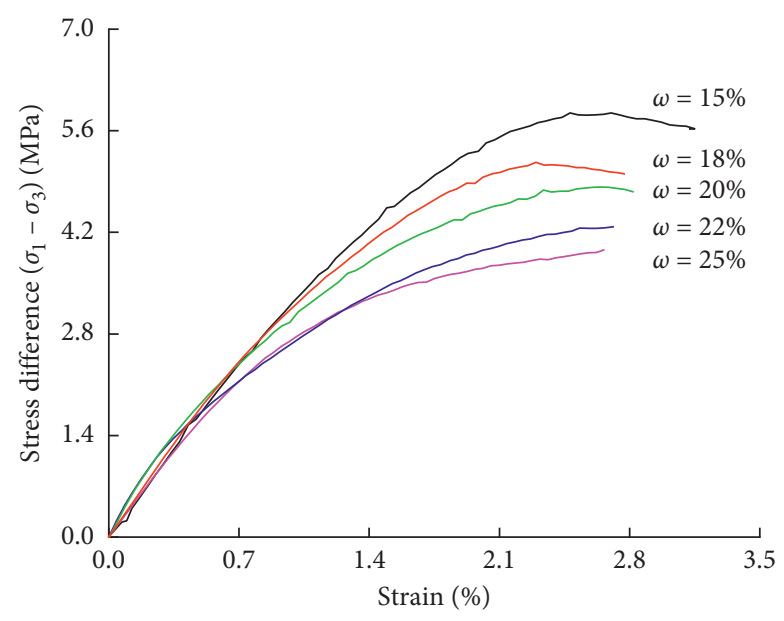

(b)

Figure 11: Stress-strain curves of the triaxial compression test of KCCFs while holding the confining pressure constant at $3 \mathrm{MPa}$. (a) Different consolidation pressures $(\omega=20 \%)$. (b) Different moisture contents $(p=3 \mathrm{MPa})$.

The cohesive stress and internal friction angle of the KCCFs calculated from the triaxial compression testing results under different confining pressures are shown in Figure 12. It can be seen that the cohesive stress is between $0.6 \mathrm{MPa}$ and $1.2 \mathrm{MPa}$ and the internal friction angle is between $15^{\circ}$ and $22^{\circ}$. With the increase of consolidation pressure and the decrease of moisture content, both the cohesive stress and the internal friction angle decrease linearly. When the consolidation pressure increases from $0 \mathrm{MPa}$ to $6 \mathrm{MPa}$, the cohesive stress and the internal friction angle of the filling material increase by $0.45 \mathrm{MPa}$ and $6.3^{\circ}$, respectively. When the moisture content increases from $15 \%$ to $25 \%$, the cohesive stress and the internal friction angle decrease by $0.34 \mathrm{MPa}$ and $3.7^{\circ}$, respectively. Therefore, both the consolidation pressure and the moisture content can have a great influence on the cohesive stress and the internal friction angle of the KCCFs. It is necessary to take appropriate mechanical parameters for different geological structures so as to make the calculation results consistent with the actual engineering facts.

3.4. Seepage Characteristics. Figure 13 shows the variation of pore water pressure gradient with time when the axial pressure is $6 \mathrm{MPa}$ and the moisture content is $20 \%$. Because the water pressure at one end is $1 \mathrm{MPa}$ and the other end is a free surface during the test, there is only one decay curve of pore water pressure gradient with respect to time. Due to the large discreteness of the test data, fourth-order polynomial fitting is introduced here. The fitting results are brought into equations (1) and (2), and the permeability is calculated by a FORTRAN program.

The test results of the permeability of the KCCF samples under different consolidation pressures and moisture contents are shown in Figure 14, from which we can see that

(1) The values of the permeability are between $1 \times 10^{-16} \mathrm{~m}^{2}$ and $1.6 \times 10^{-15} \mathrm{~m}^{2}$. Therefore, compared with natural rocks, the KCCFs belong to low- permeability materials, close to mudstone and sandy shale [28].

(2) With the increase of the consolidation pressure, the porosity of the KCCFs gradually decreases, and the permeability decreases obviously (Figure 14(a)). When the consolidation pressure increases from $1 \mathrm{MPa}$ to $6 \mathrm{MPa}$, the permeability decreases an order of magnitude, from $1.57 \times 10^{-15} \mathrm{~m}^{2}$ to $1.36 \times 10^{-16} \mathrm{~m}^{2}$.

(3) With the increase of the initial moisture content, the porosity of the KCCFs increases, and subsequently, the permeability also increases (Figure 14(b)). When the moisture content increases from $15 \%$ to $25 \%$, the permeability increases from $4.88 \times 10^{-16} \mathrm{~m}^{2}$ to $1.01 \times 10^{-15} \mathrm{~m}^{2}$.

\section{Engineering Applications}

As an illustrative engineering application, we consider a mining area in Changzhi City, Shanxi Province of China. The structure of the mining area is in the form of graben. The strata developed in the mining area from bottom to top are successively Ordovician lower Majiagou formation, Ordovician upper Majiagou formation, Ordovician Fengfeng formation, Carboniferous Benxi formation, Carboniferous Taiyuan formation, Permian Shanxi formation, and Permian Shihezi formation, and the ground is covered by Quaternary loess [29]. The $+650 \mathrm{~m}$ level of the eastern coal seam of the mining area is located in the Permian Shanxi formation, above the Ordovician limestone water level. In the development area of water diversion KCC, the coal floor is threatened by water inrush. The lithology and mechanical parameters of the coal roof and floor are shown in Table 1. The KCC is composed of $75 \%$ loose rocks, $13 \%$ natural pores and fissures (including water and a small amount of filling material particles), and $12 \%$ filling materials. The mechanical and permeability parameters of loose rocks are set to be similar to those of siltstones, while the parameters of filling materials are selected according to the actual engineering 


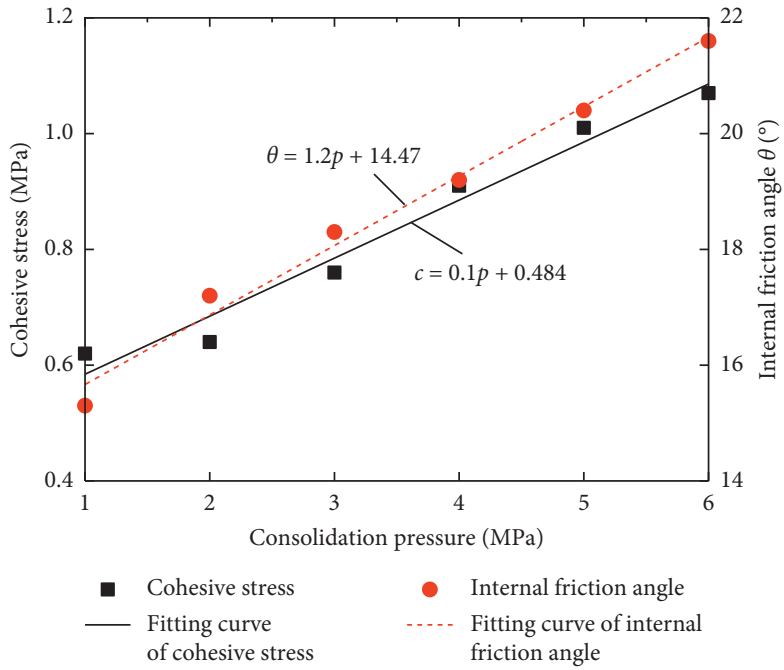

(a)

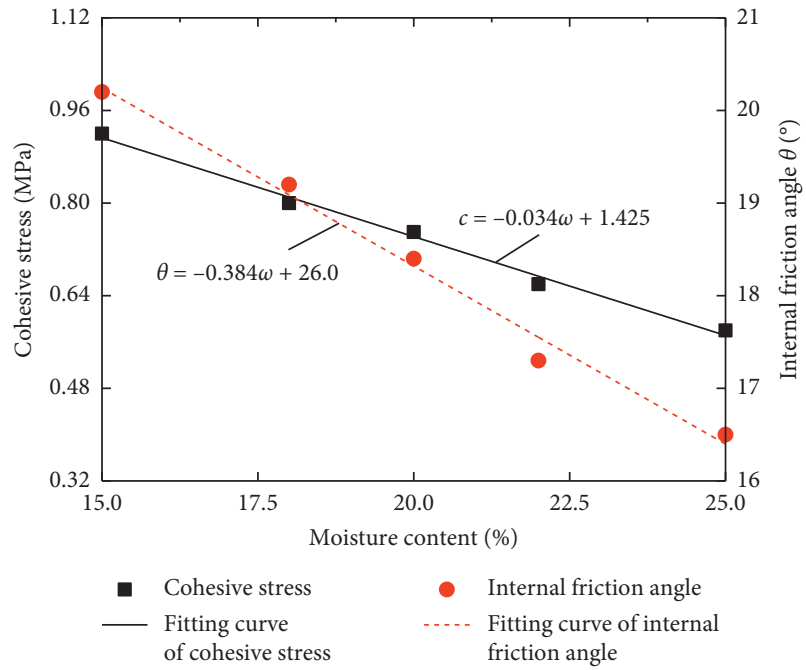

(b)

FIGURE 12: Cohesive stress and internal friction angle of KCCFs. (a) Different consolidation pressures $(\omega=20 \%)$. (b) Different moisture contents $(p=3 \mathrm{MPa})$.

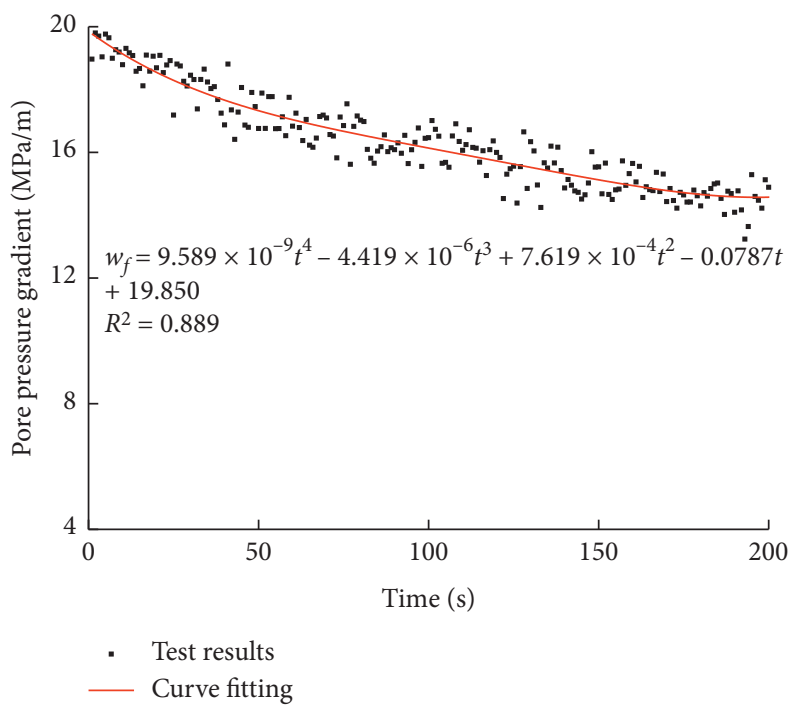

FIgURE 13: Variation of the pore water pressure gradient with time for KCCFs.

stress level (12 MPa) and moisture content (20\%) as well as the tests results in the present study.

FLAC $^{3 \mathrm{D}}$ is used to establish the plane stress model of KCC water inrush along the advancing direction of working face, as shown in Figure 15. The model is $180 \mathrm{~m}$ in width, $96.4 \mathrm{~m}$ in height, and $1.0 \mathrm{~m}$ in thickness. It contains 214664 nodes and 106380 elements. The mechanical boundary condition is set as that the top surface maintains the normal stress constant at $11.0 \mathrm{MPa}$, and the bottom surface and both sides are constrained by fixing their normal displacements. The seepage boundary condition is set as fixed water pressure of $4.5 \mathrm{MPa}$ for the bottom surface. We set the position where the collapse column was first exposed in working face as $L=0$ (Figure 15).
While simulating the advancing of working face, the advancing distance is $10 \mathrm{~m}$ each time, and the water pressure in goaf is set as 0 .

In order to simulate the influence of fillings loss on water inrush of KCC, first, it is assumed that the planar shape of loose rocks is circular, and their radii are in the range of $0.1-2.0 \mathrm{~m}$. Second, the random function built in $\mathrm{FLAC}^{3 \mathrm{D}}$ is used to randomly distribute these loose rocks in the KCC (note that the adjacent two rocks cannot intersect). Then, considering that the KCCFs will gradually move to low pressure zone under the long-term hydraulic action, $80 \%$ of them set to be distributed at the top of the KCC and $20 \%$ at the bottom of the KCC [31]. Finally, traverse all the KCC elements, and set the remaining elements other than loose 


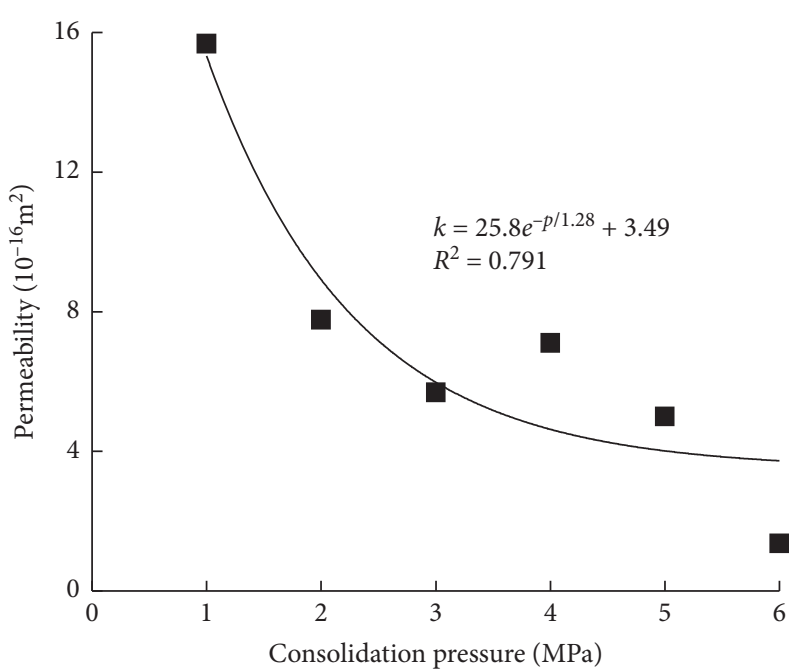

Test data Curve fitting

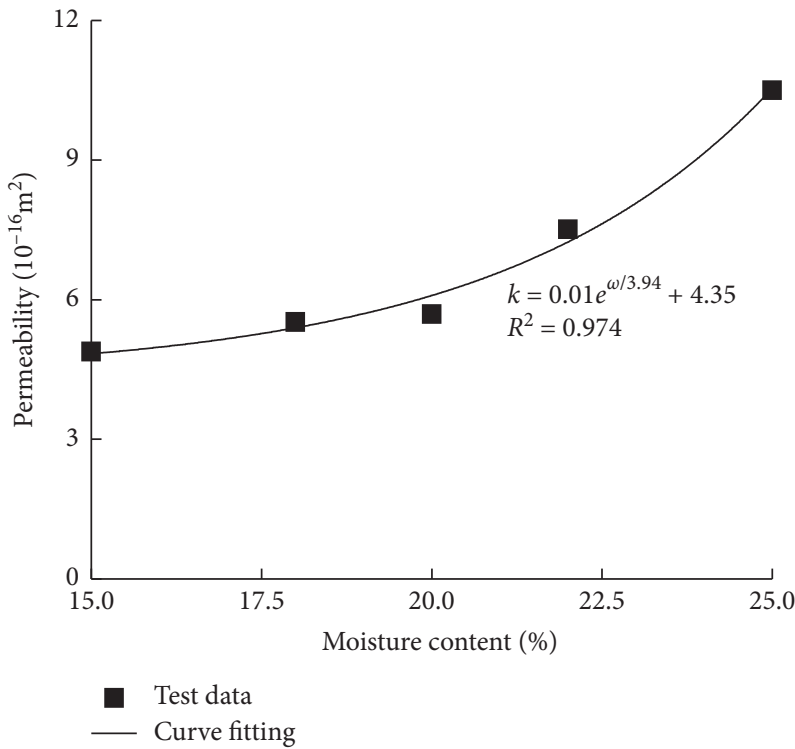

(b)

Figure 14: Permeability of KCCFs. (a) Different consolidation pressures $(\omega=20 \%)$. (b) Different moisture contents $(p=3 \mathrm{MPa})$.

TABLE 1: The lithology and mechanical parameters of the coal roof and floor [29, 30].

\begin{tabular}{lccccccccc}
\hline Items & $\begin{array}{c}\text { Thickness } \\
(\mathrm{m})\end{array}$ & $\begin{array}{c}\text { Density } \\
\left(\mathrm{kg} / \mathrm{m}^{3}\right)\end{array}$ & $\begin{array}{c}\text { Elastic } \\
\text { modulus } \\
(\mathrm{GPa})\end{array}$ & $\begin{array}{c}\text { Poisson's } \\
\text { ratio }\end{array}$ & $\begin{array}{c}\text { Cohesive } \\
\text { stress } \\
(\mathrm{MPa})\end{array}$ & $\begin{array}{c}\text { Internal } \\
\text { friction } \\
\text { angle }\left({ }^{\circ}\right)\end{array}$ & $\begin{array}{c}\text { Tensile } \\
\text { strength } \\
(\mathrm{MPa})\end{array}$ & $\begin{array}{c}\text { Porosity } \\
\text { conductivity } \\
(\mathrm{m} / \mathrm{s})\end{array}$ \\
\hline $\begin{array}{l}\text { Medium fine } \\
\text { sandstone }\end{array}$ & 22.4 & 24.0 & 32.74 & 0.23 & 19.46 & 31 & 10.0 & 0.10 & $1.0 \times 10^{-8}$ \\
$\begin{array}{l}\text { Sandy mudstone } \\
\text { Carbonaceous }\end{array}$ & 9.5 & 24.0 & 28.65 & 0.29 & 16.27 & 32 & 9.50 & 0.18 & $5.0 \times 10^{-8}$ \\
mudstone & 12.0 & 24.0 & 18.74 & 0.23 & 9.01 & 34 & 1.02 & 0.13 & $1.0 \times 10^{-8}$ \\
$\begin{array}{l}\text { Coal rock } \\
\text { Mudstone }\end{array}$ & 6.7 & 11.0 & 1.96 & 0.35 & 2.52 & 40 & 0.81 & 0.3 & $2.0 \times 10^{-7}$ \\
$\begin{array}{l}\text { Siltstone } \\
\text { Limestone }\end{array}$ & 12.8 & 24.0 & 18.74 & 0.24 & 10.24 & 33 & 1.02 & 0.14 & $1.0 \times 10^{-8}$ \\
aquifer & 20.5 & 24.0 & 18.74 & 0.23 & 9.25 & 34 & 1.02 & 0.15 & $2.0 \times 10^{-8}$ \\
KCC loose rock & - & 22.0 & 21.53 & 0.28 & 14.56 & 35 & 2.84 & 0.35 & $2.0 \times 10^{-6}$ \\
$\begin{array}{l}\text { Natural pores } \\
\text { and fissures }\end{array}$ & - & 23.5 & 17.58 & 0.24 & 10.52 & 34 & 2.05 & 0.15 & $1.5 \times 10^{-8}$ \\
KCCFs & - & 20.2 & 0.05 & 0.46 & 0 & 3 & 0 & 0.9 & $5.0 \times 10^{-6}$ \\
\hline
\end{tabular}

rock and fillings as natural fissures. In this study, a natural fissure is simplified as a solid element with a small amount of interstitial particles to participate in the fluid-solid coupling calculation. The mechanical parameters of this solid element are very small while its permeability parameters are very large. These parameters are given in Table 1.

When the mining face keeps approaching the KCC, the crack field of the surrounding rocks will connect with the KCC, resulting in the migration and loss of the filling material of KCC through the water flowing fissures due to yielding activation. The porosity and permeability of the KCCFs in the yield area are dynamically changed according to the following two formulas [32].

$$
\begin{array}{r}
\frac{\partial \varphi}{\partial t}=\lambda(1-\varphi) \rho v \\
\frac{k}{k_{0}}=\left(\frac{\varphi}{\varphi_{0}}\right)^{3}\left(\frac{1-\varphi_{0}}{1-\varphi}\right)^{2},
\end{array}
$$

where $\rho$ is the particle content of the fillings, $v$ is the seepage velocity, $\varphi_{0}$ and $\varphi$ denote the initial and current porosity of the fillings, respectively, and $k_{0}$ and $k$ designate the initial and current permeability of the fillings, respectively. $\lambda$ is the porosity change rate of the KCC element due to its internal particles being taken away in unit time. In the present study, we set $\lambda=10^{-3}$. 
$11.0 \mathrm{MPa}$

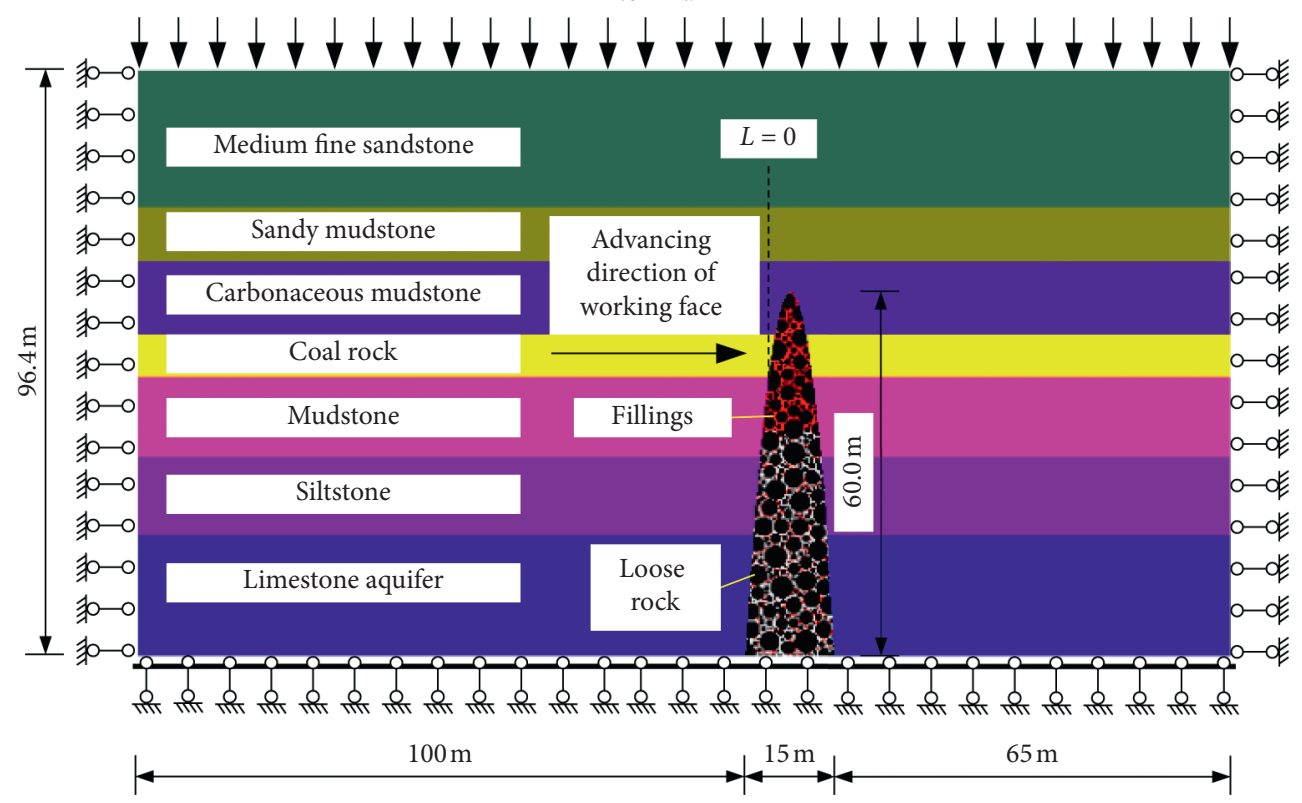

FIgURE 15: Numerical simulation model of KCC water inrush.

Changing the distance $L$ between the working face and the KCC, the variation of the vertical displacement of the coal seam floor perpendicular to the direction of the working face is shown in Figure 16. It can be seen that with the advancement of the working face, the floor behind the working face will bulge, and the uplift is proportional to its distance from the working face. However, the floor about $40 \mathrm{~m}$ in front of the working face will produce a certain subsidence due to the increase of roof overburden pressure. When $L=-14 \mathrm{~m}$, the floor uplift behind the working face and the floor subsidence in front of the working face reach their maximum values, about $92 \mathrm{~mm}$ and $86 \mathrm{~mm}$, respectively. When the KCC is exposed in the working face ( $L=16 \mathrm{~m}$ or $L=46 \mathrm{~m}$ ), the roof rock mass far behind the working face will collapse to the floor, resulting in the floor uplift therein unchanged. However, the coal seam floor at the KCC will change from subsidence to uplift. The uplift value will continue to increase with the advancing of the working face and ultimately will be much larger than other positions.

The quantity of water inflow from the coal seam floor varies with the advancing distance of working face (Figure 17). When the distance between the working face and the KCC is less than $-14 \mathrm{~m}$, the existence of the KCC has little influence on the water inflow from the coal seam floor. At this time, the unbalanced rate of water flow per unit width of the working face is about $1 \times 10^{-3} \mathrm{~m}^{3} / \mathrm{s}$ to $6 \times 10^{-3} \mathrm{~m}^{3} / \mathrm{s}$. When $L>-14 \mathrm{~m}$, the surrounding rock crack field will be connected with the KCC, which leads to the filling material in the KCC begin to yield and activate, and the particles continue to lose, the water blocking capacity of the fillings gradually decreases, and then, the water inflow of the whole coal seam floor increases, showing obvious nonlinear mutation characteristics. When $L=36 \mathrm{~m}$, the unbalanced rate of water flow per unit width of the coal seam floor will reach

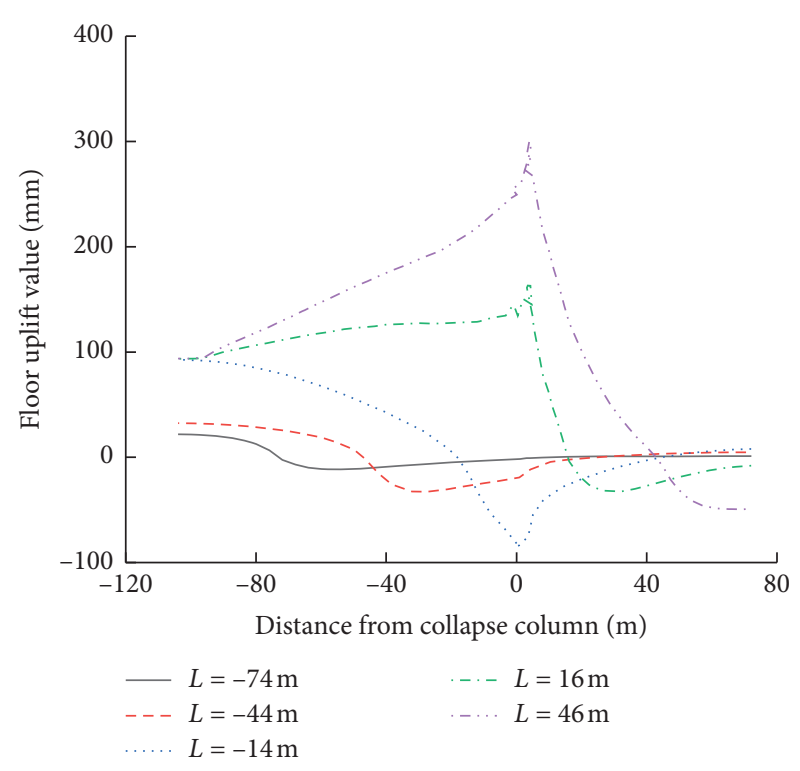

FIgURE 16: Variation of the vertical displacement (uplift) with respect to the distance between coal floor and the KCC.

to $0.26 \mathrm{~m}^{3} / \mathrm{s}$, dramatically exceeding the designed drainage capacity of the working face, which means that severe water disaster accidents will occur in the working face at this time.

Figure 18 shows the variation of the hydraulic conductivity of KCC with advancing distance of the working face. When the distance between the working face and the KCC is less than $-14 \mathrm{~m}$, the mining of the coal seam has little influence on the whole KCC, and the filling material of the KCC is in the inactive state. Thus, the KCCF still maintain effective water blocking capacity. When $L=-14 \mathrm{~m}$, the coal rock crack field in front of the working face will be connected with the KCC, which leads to the local activation and loss of 


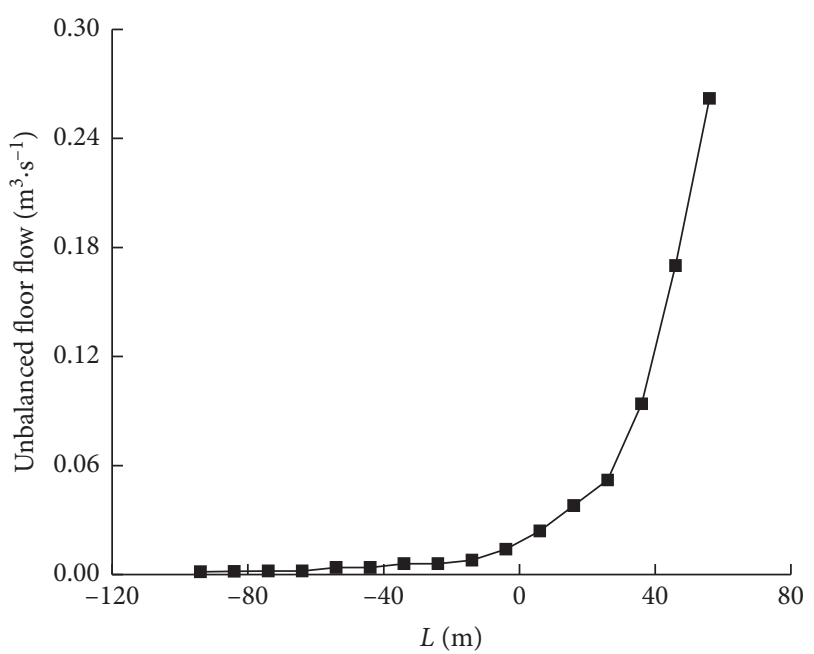

FIGURE 17: Variation of the unbalanced rate of water inflow per unit width of the coal seam floor with respect to the distance between the working face and the KCC.

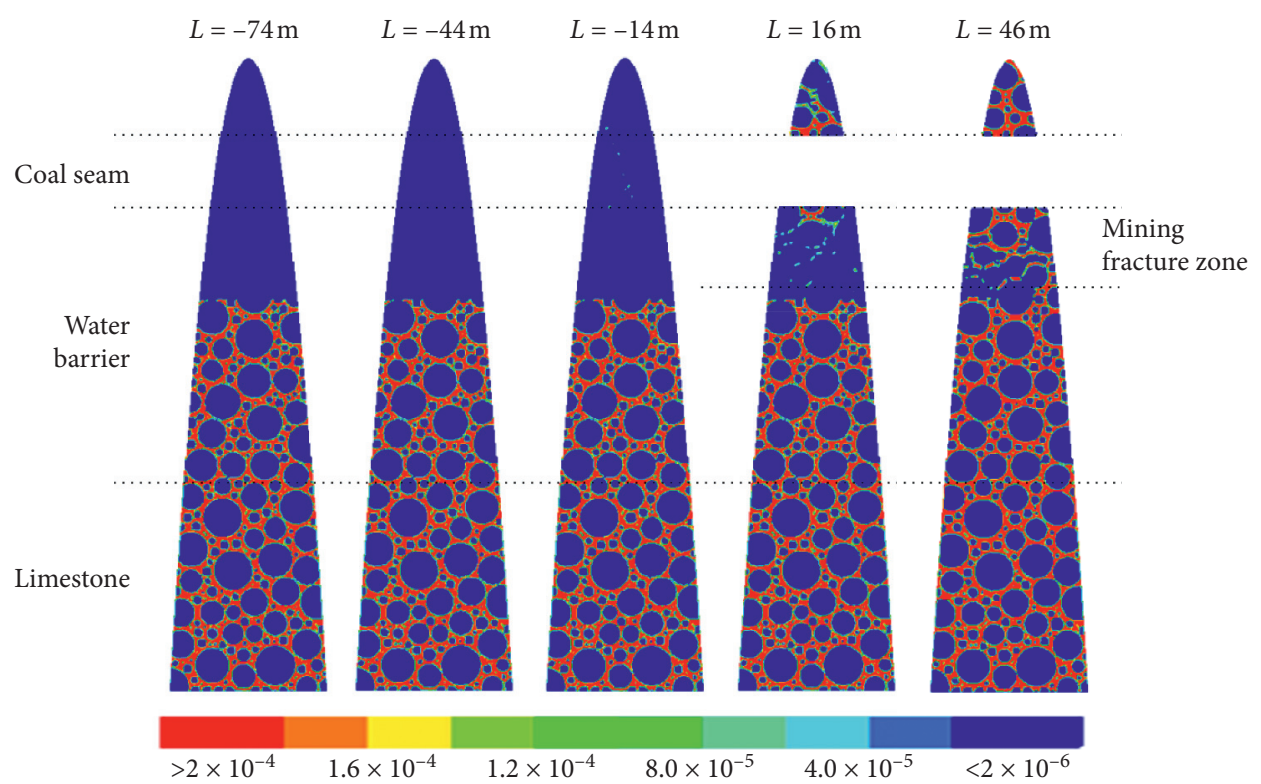

FIGURE 18: Hydraulic conductivity of KCCFs at different advancing distances of the working face.

the filling material, elevating its hydraulic conductivity. When $L=16 \mathrm{~m}$, the coal mining process will expose the KCC, which will lead to the serious loss of the filling material particles of KCC in the area about $6 \mathrm{~m}$ below the coal seam, and the water blocking capacity of the KCC will become lower and lower. When the working face further advances ( $L=46 \mathrm{~m}$ ), a large number of the filling material particles of the KCC above the limestone aquifer are lost, forming an obvious intersection network of water channels. The water blocking capacity of the KCC is nearly lost, resulting in the inrush of the confined water in the limestone under the coal seam to the mining face through cracks and fissures between the loose rocks of the KCC.

It can be concluded from the above discussion that the migration and loss of the filling material particles of the KCC is the fundamental reason for the lagging water inrush phenomenon of the KCC. It is of great significance to study the mechanical and permeability characteristics of the filling material of the KCC for the establishment and improvement of a water inrush system of the KCC.

\section{Conclusions}

In this study, the dehydrated consolidation method is used to prepare the samples of KCCFs with different consolidation pressures and moisture contents. The uniaxial compression test, Brazilian split test, conventional triaxial compression test, and the permeability test are carried out. The uniaxial compressive strength, splitting tensile strength, cohesive stress, internal friction angle, and permeability of 
the KCCFs are calculated, and the variation of the above mechanical properties with respect to the consolidation pressure and moisture content is analyzed. The main conclusions of the present study are as follows:

(1) KCCFs show obvious soft rock characteristics in uniaxial compression and Brazilian split tests. The ratio of the uniaxial compressive strength to splitting tensile strength is between $12: 1$ and $8: 1$. The larger the consolidation pressure or the smaller the moisture content, the larger the ratio of the tensile strength to compressive strength.

(2) Under a certain confining pressure, the KCCFs show similar plastic yield characteristics as soil. The cohesive stress and the internal friction angle do not change significantly with the plastic strain.

(3) With the increase of the consolidation pressure or the decrease of the moisture content, the uniaxial compressive strength, elastic modulus, splitting tensile strength, cohesive stress, and internal friction angle of the KCCFs increase linearly, while the permeability increases exponentially.

(4) The range of the mechanical properties of the KCCFs are 1.57-3.15 MPa for uniaxial compressive strength, $0.14-0.32 \mathrm{MPa}$ for splitting tensile strength, 0.15-0.30 GPa for elastic modulus, 0.6-1.2 MPa for cohesive stress, $15^{\circ}-22^{\circ}$ for internal friction angle, and $4.88 \times 10^{-16}$ to $1.49 \times 10^{-15} \mathrm{~m}^{2}$ for permeability.

(5) With the advancing of the working face, when the cracks of the surrounding rocks of the stope are connected with the KCC, the KCCFs will continue to yield, activate, and migrate due to the effect of fluidsolid coupling. This will increase the overall hydraulic conductivity of the KCC and finally trigger the lagging water inrush phenomenon.

\section{Data Availability}

The data used to support the findings of this study are available from the corresponding author upon request.

\section{Conflicts of Interest}

The authors declare that they have no conflicts of interest.

\section{Acknowledgments}

This work was supported by the National Natural Science Foundation of China (51708185, 41807209, and 51778215), the Young Teacher Foundation of HPU (2019XQG-19), the Henan Provincial Youth Talent Promotion Program (2020HYTP003), and the Doctor Foundation of Henan Polytechnic University (B2017-51, B2017-53, and B201564). The authors want to acknowledge these financial assistances. In addition, the authors would like to thank LetPub (http://www.letpub.com) for its linguistic assistance during the preparation of this article.

\section{References}

[1] H. Xie, X. Zhao, J. Liu, R. Zhang, and D. Xue, "Influence of different mining layouts on the mechanical properties of coal," International Journal of Mining Science and Technology, vol. 22, no. 6, pp. 749-755, 2012.

[2] Q. Wu, B. Li, and Y. L. Chen, "Vulnerability assessment of groundwater inrush from underlying aquifers based on variable weight model and its application," Water Resources Management, vol. 30, no. 10, pp. 3331-3345, 2016.

[3] Q. Wu, Y. Z. Liu, and L. Yang, "Using the vulnerable index method to assess the likelihood of a water inrush through the floor of a multi-seam coal mine in China," Mine Water and the Environment, vol. 30, no. 1, pp. 54-60, 2011.

[4] M. C. He, H. P. Xie, S. P. Peng et al., "Study on rock mechanics in deep mining engineering," Chinese Journal of Rock Mechanics and Engineering, vol. 24, no. 16, pp. 2803-2813, 2016, in Chinese.

[5] X. X. Miao and M. G. Qian, "Research on green mining of coal resources in China: current status and future prospects," Journal of Mining \& Safety Engineering, vol. 26, no. 1, pp. 1-14, 2009, in Chinese.

[6] Q. Wu, X. Jia, D. T. Cao et al., "Impermeability evaluation method and its application on the ancient weathering crust of carbonatite in middle Ordovician system in North China coal field," Journal of China Coal Society, vol. 39, no. 8, pp. 1735-1741, 2014, in Chinese.

[7] B. Y. Zhang and Z. B. Lin, "Seepage property of crushed mudstone rock in collapse column," Advances in Civil Engineering, vol. 2020, Article ID 8866697, 10 pages, 2020.

[8] D. Ma, J. J. Wang, and Z. H. Li, "Effect of particle erosion on mining-induced water inrush hazard of karst collapse pillar," Environmental Science and Pollution Research, vol. 26, no. 19, pp. 1-10, 2019.

[9] S. X. Yin, Q. Wu, and S. X. Wang, "Studies on characters and forming mechanism of karst collapse column at mine area of North China," Chinese Journal of Rock Mechanics and Engineering, vol. 13, no. 1, pp. 120-123, 2004, in Chinese.

[10] J. C. Wang and J. B. Li, "Physical model and theoretic criterion of the forecast of water inrush caused by collapse columns," Journal of University of Science and Technology Beijing, vol. 32, no. 10, pp. 1243-1247, 2010, in Chinese.

[11] X. G. Hou, W. Shi, and T. Yang, "A non-linear flow model for the flow behavior of water inrush induced by the karst collapse column," RSC Advances, vol. 8, no. 3, pp. 1656-1665, 2018.

[12] H. Bai, D. Ma, and Z. Chen, "Mechanical behavior of groundwater seepage in karst collapse pillars," Engineering Geology, vol. 164, pp. 101-106, 2013.

[13] Y. Q. Song, X. Y. Wang, P. Cheng et al., "The mechanical criterion and numerical simulation of thick-walled elliptical cylinder collapse column model under water inrush," Journal of China Coal Society, vol. 36, no. 3, pp. 452-455, 2011, in Chinese.

[14] Z.-h. Li, G.-r. Feng, and C.-z. Zhai, "Study on "triangle" waterinrush mode of strong water-guide collapse column," Journal of Central South University, vol. 23, no. 9, pp. 2402-2409, 2016.

[15] J. B. Li, "Water inrush from pregrouting fractures induced by mining activities and its engineering control method optimization," Advances in Civil Engineering, vol. 2019, Article ID 6243609, 10 pages, 2019.

[16] W. H. Shi, T. H. Yang, and S. B. Yu, "Experimental investigation on non-Darcy flow behavior of granular limestone 
with different porosity," Journal of Hydrologic Engineering, vol. 25, no. 08, 11 pages, Article ID 06020004, 2020.

[17] B. Yao, J. Wei, D. Wang et al., "Numerical study on seepage property of karst collapse columns under particle migration," CMES: Computer Modeling in Engineering and Sciences, vol. 91, no. 2, pp. 81-100, 2013.

[18] J. C. Wang, J. B. Li, and G. M. Xu, "Development and application of simulation test system for water inrush from the water-conducting collapse column," Journal of Mining and Safety Engineering, vol. 27, no. 3, pp. 305-309, 2010, in Chinese.

[19] W. Q. Liu, X. X. Miao, W. Yu et al., "A testing method for determining the gas permeability of over broken rocks," Journal of Experimental Mechanics, vol. 21, no. 3, pp. 399-402, 2006.

[20] D. Ma, H. Bai, Z. Chen, and H. Pu, "Effect of particle mixture on seepage properties of crushed mudstones," Transport in Porous Media, vol. 108, no. 2, pp. 257-277, 2015.

[21] X. Miao, S. Li, Z. Chen, and W. Liu, "Experimental study of seepage properties of broken sandstone under different porosities," Transport in Porous Media, vol. 86, no. 3, pp. 805-814, 2011.

[22] T. J. Zhang, H. B. Shang, S. G. Li et al., "Permeability tests of fractured sandstone with different sizes of fragments under three-dimensional stress states," Rock and Soil Mechanics, vol. 39, no. 7, pp. 2361-2370, 2018, in Chinese.

[23] W. L. Li, J. Q. Zhou, X. L. He et al., "Nonlinear flow characteristics of broken granite subjected to confining pressures," Rock and Soil Mechanics, vol. 38, no. S1, pp. 146-156, 2017, in Chinese.

[24] H. S. Song, J. H. Li, and B. Y. Zhang, "Study on the detection and prevention methods of collapse column X3 in Sima coal mine," Energy Technology and Management, vol. 43, no. 4, pp. 163-164, 2018, in Chinese.

[25] W. F. Brace, J. B. Walsh, and W. T. Frangos, "Permeability of granite under high pressure," Journal of Geophysical Research, vol. 73, no. 6, pp. 2225-2236, 1968.

[26] N. Ademovic and A. Kurtovic, "Influence of planes of anisotropy on physical and mechanical properties of freshwater limestone (Mudstone)," Construction and Building Materials, vol. p268, p. 19, Article ID 121174, 2021.

[27] H. J. Su, Y. J. Feng, Q. Z. Guo et al., "Model experimental study on the seepage and failure features of tunnel under wetting-drying alternation with increasing water pressure," Geofluids, vol. 2020, Article ID 8845528, 11 pages, 2020.

[28] Y. S. Li, Z. G. Ma, and Y. L. He, "Experimental research on permeability of rocks of coal bearing strata," Journal of Experimental Mechanics, vol. 21, no. 2, pp. 129-133, 2006, in Chinese.

[29] J. F. Zhang, H. L. Zhang, D. Meng et al., "Numerical simulation of rock deformation and seepage field with a fully-water karst collapse column under mining influence," Chinese Journal of Rock Mechanics and Engineering, vol. 28, no. S1, pp. 2824-2829, 2009, in Chinese.

[30] Z. B. Lin, B. Y. Zhang, and J. Q. Guo, "Analysis of a waterinrush disaster caused by coal seam subsidence karst collapse column under the action of multi-field coupling in Taoyuan coal mine," Computer Modeling in Engineering and Sciences, vol. 126, no. 1, pp. 2225-2236, 2021.

[31] L. Niu, Water inrush mechanism and risk assessment research of karst collapse column in North China coal field, $\mathrm{PhD}$ Dissertation, China University of Mining and Technology, Beijing, China, 2015.
[32] K. Zhang, B. H. Yao, S. G. Wu et al., "Study on the characteristics of variable mass seepage and water inrush mechanism of collapse column," Journal of Mining and Safety Engineering, vol. 30, no. 6, pp. 892-896, 2013, in Chinese. 